\title{
A Tentative Interpretation of the Epistemological Significance of the Encrypted Message Sent by Newton to Leibniz in October 1676
}

\author{
Jean G. Dhombres \\ Centre Alexandre Koyré-Ecole des Hautes Etudes en Sciences Sociales, Paris, France \\ Email: jean.dhombres@damesme.cnrs.fr
}

Received October $8^{\text {th }}, 2013$; revised November $9^{\text {th }}, 2013$; accepted November $16^{\text {th }}, 2013$

\begin{abstract}
Copyright (C) 2014 Jean G. Dhombres. This is an open access article distributed under the Creative Commons Attribution License, which permits unrestricted use, distribution, and reproduction in any medium, provided the original work is properly cited. In accordance of the Creative Commons Attribution License all Copyrights (C) 2014 are reserved for SCIRP and the owner of the intellectual property Jean G. Dhombres. All Copyright (C) 2014 are guarded by law and by SCIRP as a guardian.
\end{abstract}

In Principia mathematica philosophice naturalis (1687), with regard to binomial formula and so general Calculus, Newton claimed that Leibniz proposed a similar procedure. As usual within Newtonian style, no explanation was provided on that, and nowadays it could only be decoded by Newton himself. In fact to the point, not even he gave up any mention of Leibniz in 1726 on the occasion of the third edition of the Principia. In this research, I analyse this controversy comparing the encrypted passages, and I will show that at least two ideas were proposed: vice versa and the algebraic handing of series.

Keywords: Leibniz; Newton; Calculus Principia; Binomial Series; Controversy; Vice Versa

\section{Introduction}

In a conference devoted to resentment seen as an object for the historian, I tried to account for the vindictive attitude that Newton gradually developed towards Leibniz. What is profound in the quarrel was not really about who first discovered a path to Calculus, but how one happens to recognize a revolutionary theory in mathematics has been prepared with the requisites of rigour accepted at a certain time. And more, it is to know how it is possible to ensure that a new theory is actually completed. I then necessarily reduced my presentation of mathematical facts, emphasizing only on the perception of an innovator in science, who may imagine accordingly that any other creator was to succeed only by following the same path ${ }^{1}$. Resentment may then arise from the almost experimental recognition that this almost automatic thought is not true. Public sources on the so-called priority quarrel between Newton and Leibniz, which began in 1699 through the fault of Nicolas Fatio de Duillier, are numerous enough to afford such a psychological study ${ }^{2}$. But more can be said, outside any theory of emotions. Here I am to focus on a purely epistemological aspect, restricting even to a specific expression, precisely the one given by what is called the epistola posterior. The name was coined by Newton himself to refer to the second letter he wrote in Oc-

\footnotetext{
${ }^{1}$ Voir Jean Dhombres, is it interesting to qualify as resentment some episodes of the priority quarrel between Leibniz and Newton? Reflexions on pyschological aspects in history of science, Geneva colloquium of October 2012 on Resentment, under the responsability of Dolorès Martín Moruno, to appear.

${ }^{2}$ See: Rupert Hall, 1980; Koyré, 1968; Newton, 1999; Whiteside, 1960; Whiteside (ed.), 1967-1974; Guicciardini, 1998; Panza, 2005; Harper, 2011; Dhombres, forthcoming 1.
}

tober 1676 to Leibniz. In it Newton explained that he had a method for dealing with "quantities" (not yet said variable but flowing ${ }^{3}$ ), when related by an equation, and that there was a double reciprocal link between these quantities and their speed of change, called fluxions ${ }^{4}$. Newton wrote about a "vice versa" procedure (Figure 1). It has always been thought that this meant the relation between differential and integral calculus ${ }^{5}$. Newton mingled the procedure, so is his precise verb, with the way to handle series algebraically. I just quote the memorandum found in Newton's papers, but give translation of the two deciphered parts only.

My paper confronts the fact that the meaning of what was encrypted, which included at least two ideas (one is the vice versa and the other is the algebraic handing of series), could only be decoded by Newton himself. In his famous Principia mathematica philosophice naturalis in 1687, eleven years later, Newton claimed that Leibniz had a similar procedure, but there he did not explain the vice versa. I am not sure, contrary to what Hall was thinking, that this attitude of Newton helped to clarify

\footnotetext{
${ }^{3}$ The expression for a variable was invented by de L'Hôpital in Analyse des infiniment petits, a book published in 1696 at the Imprimerie royale in Paris. The expression "to flow" was sometimes used in Latin by Cavalieri in 1635, to describe the move of a straight line through a given geometric figure.

${ }^{4}$ The vocabulary for fluxions was settled in Newton's manuscripts around 1671 , but was used earlier around 1666 , which is by the way only ten years before 1676.

${ }^{5}$ Remark that this common thought is based on the idea that computation with fluxions and its inverse, which is obtaining fluents from fluxions, is exactly the same as differential and integral calculus. That this idea was the principle on which a biased judgment of the Royal Society had been founded against Leibniz in the early $18^{\text {th }}$ century should prevent us from accepting it without any further discussion.
} 


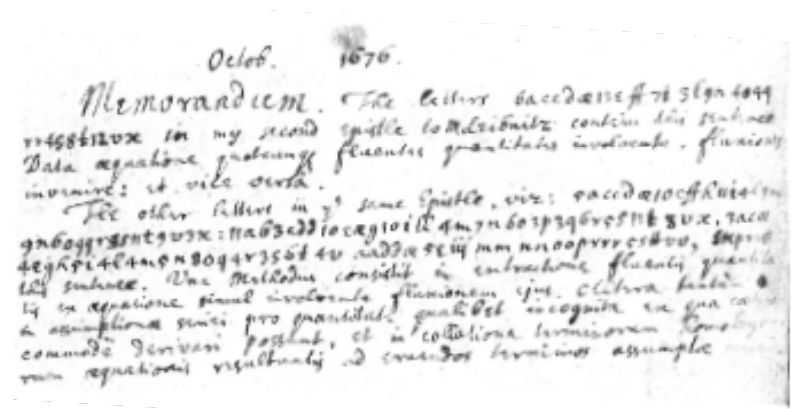

1. Given an equation involving any number of fluent quantities to find the fluxions and vice versa.

2. One method consists in extracting a fluent quantity from an equation at the same time involving its fluxion; but another by assuming a series for any unknown quantity whatever, from which the rest could conveniently be derived, and in collecting homologous terms of the resulting equation in order to elicit the terms of the assumed series ${ }^{6}$.

Figure 1.

Translations of Newton's Memorandum possibly from October1676, as it is dated, where he deciphered the two encrypted messages he sent to Leibniz.

his relationship to Leibniz ${ }^{7}$. To the point he gave up any mention of Leibniz in 1726 on the occasion of the third edition of the Principia. If my basic assumption is that Leibniz could absolutely not decipher these messages ${ }^{8}$, and Newton knew it beforehand, I make a second assumption for the present presentation. Newton would think that at least part of the non encrypted content of the letter, the one devoted to the now-called Newton's binomial, would have been enough for Leibniz to grasp the meaning of "vice versa". The link with series, binomial series in fact, has always been considered by historians as basic to the understanding of Newton's ways. In other words, to conduct the present study, I am assuming that Newton thought he had invented calculus of fluxions and its inverse on the basis of a meditation on the binomial theorem. Or, better said, Newton thought this meditation on the binomial formula provided the only reasonable access to the new Calculus. So that what is in the epistola posterior in reference to the binomial theorem should be sufficient to rebuild his inventive steps.

\section{An Outline}

The question is now to see how such a thesis can be documented. In what may also be seen as a reconstruction of Newton possible epistemological feelings ${ }^{9}$, I use some documents in addition to this second letter that I will not comment in more

${ }^{6}$ This memorandum is in the "waste-book" kept in the University Library of Cambridge (Add. 4004, fol. 81v), and with the help of Newton it was already printed by Wallis for the third volume of his Mathematical works where he put a Latin translation of his Treatise on algebra (1693). The decipherment also appeared in the Commercium Epistolicum in 1712. ${ }^{7}$ Hall, 1980.

${ }^{8}$ By the way, some letters are missing in the second coding, see Turnbull, 1960, p. 159.

${ }^{9} \mathrm{I}$ am using this terminology in order to avoid a contemporary tendency to reduce epistemology to logic and to an analytic side, thus destroying what Gaston Bachelard analyzed so carefully, under the name of "obstacle épistémologique". Very roughly speaking, it is a process of thought by which something cannot be discovered or even expressed because common views prevent any investigation on this side. Kuhn modified this idea with the notion of a paradigm, or model for normal science at a time, thus replacing common views, but requiring an external object not fitting to the paradigm and its logic, the explanation of which will then destroy normal science, to get another one. details ${ }^{10}$. But I selected few other documents, and in fact only three authors will help me. First, Nicolaus Mercator, of whom John Wallis presented a paper to the Philosophical Transactions in 1668. It is generally acknowledged that this paper made an impression on Newton; he even might have thought that his deepest and unpublished thoughts had been discovered. So my purpose is to check from Newton's second letter what could have been analogous in Mercator's Logarithmotechnia. On the other hand, I will quote Gregory of Saint-Vincent ${ }^{11}$, as his name appeared in a note by Christiaan Huygens for the Académie royale des science the same year 1668, when he precisely commented Mercator's results, and wanted to give a more balanced history than the one essentially based on Wallis that Mercator had provided.

But before going to this year 1668, when absolutely nothing about fluxions had been known outside Newton, I have to make clear, at least from our actual point of view, what precisely binomial formula could teach. It seems to me that this way, perhaps even because of its anachronistic position, helps understanding the past. The only condition is to always confront with what we know about the available knowledge in the past, as discussed by the available historiography. So history of science has to engage not only a confrontation between two periods of time, but with the tradition as well.

\section{What the Binomial Formula May Provide about Newton's Vice Versa Formulation?}

Newton's Binomial formula is the development in power series of a given power of a binomial, generally written nowadays as $(1+x)$, the power being $\alpha$, in fact any number:

$$
\begin{aligned}
(1+x)^{\alpha}= & 1+\alpha x+\frac{\alpha(\alpha+1)}{2 !} x^{2}+\cdots \\
& +\frac{\alpha(\alpha-1) \cdots(\alpha-n+1)}{n !} x^{n}+\cdots
\end{aligned}
$$

This formula has a finite number of terms when exponent $\alpha$ is an integer, thus providing what is called Pascal's triangle. Except that coefficients in (1) are analyzed, while in Pascal's triangle they are computed through an iterative construction. The second member of (1) is an infinite series for all other values of $\alpha$, even when $\alpha=-1$, and this particular case will play a leading role. The binomial series may be considered as a definition of an exponential, and so is the case by Cauchy in his 1821 Cours d'Analyse algébrique, for which it was necessary to consider limitations on values of $x$, so that to ensure convergence of the series (in fact the modulus of $x$, or its absolute value if one restricts to real values, should be strictly less than 1). In 1676, nobody except Gregory of Saint-Vincent had provided a definition of an exponential when an irrational exponent $\alpha$ was at stake. Newton's formulation of the binomial was explicitly restricted to rational exponents, and even in this

\footnotetext{
${ }^{10}$ The second letter of 1676 Newton intended for Leibniz through Oldenburg acting as secretary of the Royal Society established ten years earlier, is available in Latin and in an English translation in Turnbull (ed.), 1960, vol. II, pp. 110-161. A French translation was given in the thesis of Michel Pensivy, 1987. I am not analyzing the whole letter, and as in a stylistic exercise, concentrate on the binomial formula only.

${ }^{11}$ Jesuit fathers usually named him by his first name, in Latin, Gregorius. The name in French, Grégoire de Saint-Vincent, was not used at the time, and in 1668 for the Paris Academy of science, Huygens used the form Gregorius de Sancto Vincentio. I will use the form Gregory of Saint-Vincent.
} 
case he did not attempt a proper definition. There has been however an earlier use by Wallis with the square root of 3 .

Let us integrate the left member of (1), under the restriction $\alpha \neq-1$. One side gives an integration result,

$$
\int_{0}^{x}(1+t)^{\alpha} \mathrm{d} t=\frac{(1+x)^{\alpha+1}}{\alpha+1}-\frac{1}{\alpha+1}
$$

and so we deduce by applying (1) in the case of exponent $\alpha+1$, then dividing by $\alpha+1$, and with the elimination of the constant term:

$$
\begin{aligned}
\int_{0}^{x}(1+t)^{\alpha} \mathrm{d} t= & x+\frac{\alpha}{2 !} x^{2}+\cdots \\
& +\frac{\alpha(\alpha-1) \cdots(\alpha-n+2)}{n !} x^{n}+\cdots
\end{aligned}
$$

From the second member of (1), we may compute in a different way, this time using formal integration term by term of every power of $x$, and here there is a need for a more specialized integration result

$$
\int_{0}^{x} t^{n} \mathrm{~d} t=\frac{x^{n+1}}{n+1}
$$

By this process, the first member of (1) becomes the first member of (2), and the second member of (1) becomes another series, so that one has:

$$
\begin{aligned}
\int_{0}^{x}(1+t)^{\alpha} \mathrm{d} t= & x+\alpha \frac{x^{2}}{2}+\cdots \\
& +\frac{\alpha(\alpha-1) \cdots(\alpha-(n-1)+1)}{(n-1) !} \frac{1}{n} x^{n}+\cdots
\end{aligned}
$$

Fortunately the two second members of (2) and (3) are being identical once rearranged. So that one sees then that the way integration works for a $x^{n}$ or for $(1+x)^{\alpha}$, with the two formulas which were respectively used for the two previous ways along with (1), is reflected in the way coefficients of the binomial formula are behaving. But we will see that our writing of coefficients is not the way Newton wrote about to Leibniz.

In the case $\alpha=-1$, one starts from a well known particular case,

$$
\frac{1}{1+x}=1-x+x^{2}+\cdots+(-1)^{n} x^{n}+\cdots
$$

This time however, one has not another binomial to use for integration of the two members. One has to rely on a completely different situation, as the Neper logarithmic function appears.

$$
\ln (1+x)=x-\frac{x^{2}}{2}+\frac{x^{3}}{3}+\cdots+(-1)^{n-1} \frac{x^{n}}{n}+\cdots
$$

We get as well, when playing with variable $x$ (in fact changing $x$ into $-x$ in the integration process)

$$
\ln \frac{1}{1-x}=x+\frac{x^{2}}{2}+\frac{x^{3}}{3}+\cdots+\frac{x^{n}}{n}+\cdots
$$

This last result that may be visualized in the original paper (see Figure 2) was the great novelty of Mercator's Logarithmotechnia ${ }^{12}$, which had been prepared a year before. In this case attested in 1668 , one sees that coefficients of the binomial

\footnotetext{
${ }^{12}$ Mercator, 1668.
}

formula are well adapted to integration of powers of $x$.

Pay attention to the fact that I am not pretending here anything about the way Newton could have obtained the binomial formula ${ }^{13}$. He never proved it, even if this formula was essential to his Methodus fluxionum, for which there is a well established manuscript in 1671, and which was never published by Newton $^{14}$ who died in 1727 . What I will precisely be looking at is the way Newton wrote binomial formula, in his October 1676 letter to Leibniz (via Oldenburg). We will see that Newton's writing reflects the behaviour of coefficients towards integration, using in fact various integration formula, form the simple one for integer powers of $x$, even in the case of -1 , or for any power of $x$. I am then suggesting that conversely integration of powers of $x$ can be deduced from this specific writing of the binomial formula, and then, precisely from the aspect of the formula as a series, integration appears as well for any function (supposedly represented by a power series).

So that I first have to provide Newton's formulation, as it can be read in Newton's letter for the development of a binomial with a rational exponent ${ }^{15}(m$, and $n$, are integers, possibly negative, and not zero):

$$
(P+P Q)^{\frac{m}{n}}=P^{\frac{m}{n}}+\frac{m}{n} A Q+\frac{m-n}{2 n} B Q+\frac{m-2 n}{3 n} C Q+\cdots
$$

Some explanations are required. In fact, the first letter of the alphabet $A$ denotes the first term $P^{\frac{m}{n}}$ to the right of the equal sign. Newton wanted to have it so denoted so that $B$, the second letter in the alphabet, appearing in the third term of the series, denotes the second term $\frac{m}{n} A Q$. Then $C$ as third letter of the alphabet, appearing in the fourth term, is to denote the third term, and so on. Modern terminology exhibits the same play on coefficients with a displacement of a unit. I do not believe by the way that I am modifying the significance of what Newton did by putting index numbers where he used alphabetical order, and even by taking $P=1$ and $Q=x$. But I know what I am inducing when I add a functional notation in order to state the dependence of letter $A$ in $\frac{m}{n}$ (so that I write $f_{1}$ ), or $B$ (which I write $\left.f_{2}\right), C$, and so on. By using a concept not present in Newton's mind, I am trying to show as clearly as possible that Newton's binomial, as any exponential like $x^{y}$, requires two variables, one denoted by Newton as $Q$, and the other is the exponent $\frac{m}{n}$. I may then replace Newton's manner by a visible dependence of coefficients, in order to obtain the formulation:

$$
\begin{aligned}
(1+x)^{\frac{m}{n}}= & f_{1}\left(\frac{m}{n}\right)+f_{2}\left(\frac{m}{n}\right) f_{1}\left(\frac{m}{n}\right) x \\
& +f_{3}\left(\frac{m}{n}\right) f_{2}\left(\frac{m}{n}\right) f_{1}\left(\frac{m}{n}\right) x^{2}+\cdots
\end{aligned}
$$

\footnotetext{
${ }^{13}$ Whiteside, 1961.

${ }^{14}$ It is generally said that Castillon is the first to have provided a proof in 1742 for Newton's binomial formula, but in fact it appeared as early as 1708 in a textbook by Charles Reyneau, L'Analyse démontrée, with a new edition in 1736 (See Jean Dhombres, forthcoming 2). There was also a proof in Fluxionum Methodus Inversa by Cheyne in 1703.

${ }^{15}$ Newton did not use parenthesis for the binomial $P+P Q$, but he drew a line above the whole binomial, ended by a descending vertical line.
} 


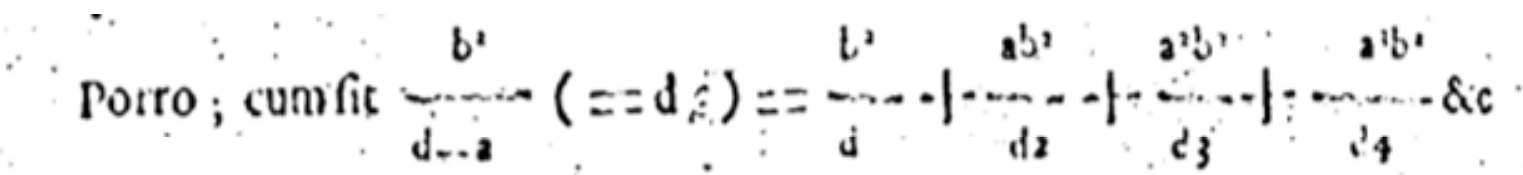

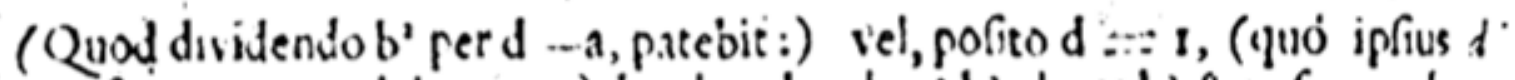
foreltacss omnci de'cin;ur, ) $b^{2}-1-a^{2}-f-a^{2} b^{2}-1-a^{2} b^{2}$ sce. Seu $t-f-a$

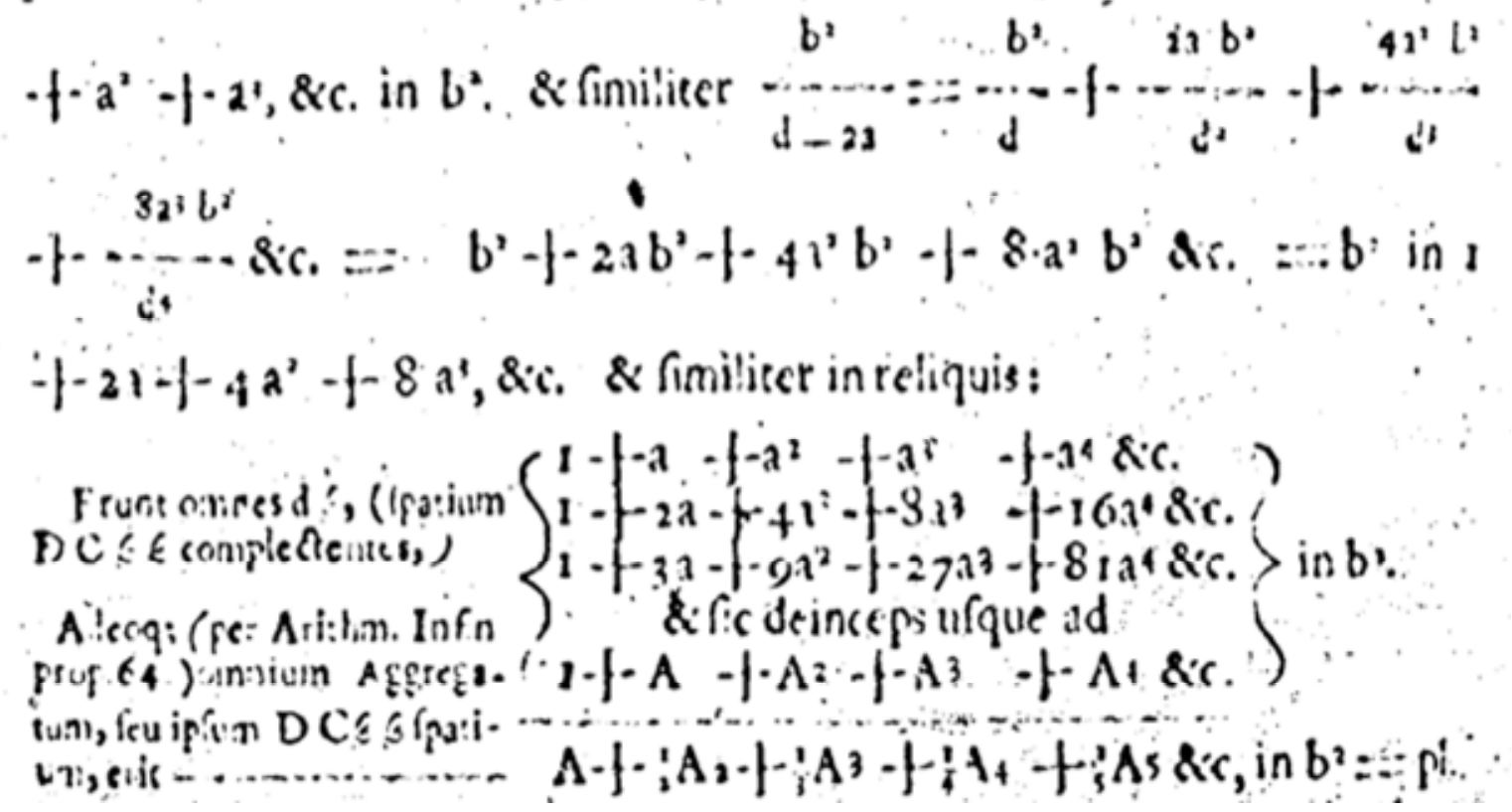

Figure 2.

A page full of computations of series, taken from Mercator by Wallis, in his presentation to the Royal Society in August 1668, p. 758. At the last line is the famous Logarithmic series (see relation (3)'), and the word quadrature is there forgotten as the abbreviation $p l$ appears, for plane area, which is interpreted as a logarithm, due to Gregory of Saint-Vincent's result as stated by de Sarasa. This formula is very efficient for small values of $A$, so that it avoids the lengthy computation of a whole table for logarithms.

I know from Newton's writing that the final result will have to be:

$$
f_{1}\left(\frac{m}{n}\right)=1, f_{2}\left(\frac{m}{n}\right), f_{3}\left(\frac{m}{n}\right)=\frac{1}{2}\left(\frac{m}{n}-1\right), f_{4}\left(\frac{m}{n}\right)=\frac{1}{3}\left(\frac{m}{n}-2\right)
$$

and more generally for

$$
k \geq 2, f_{k}\left(\frac{m}{n}\right)=\frac{\frac{m}{n}-(k-1)+1}{k-1} .
$$

In other words, these forms exhibit the very particular behaviour I am looking for, as there is a unit less taken at each successive occurrence, and a division by an integer a unit further. This is the form of the successive terms Newton chose to exhibit with $A, B, C$, etc., without exhibiting $m / n$, but for example in the form where one sees the place of successive integers like 2 and 3 in

$$
\frac{1}{3}\left(\frac{m-2 n}{n}\right) \text {. }
$$

So the general writing for coefficients as in (2), our common way of writing, is not the generality that Newton was interested in. For the use of Leibniz, he preferred to focus on the double behaviour for integers. The proper gymnastic on the generality of variable $\frac{m}{n}$, for which one has to add a unit (which corre- sponds to the integration in $x$ of power $\left.(1+x)^{\frac{m}{n}}\right)$, is an integration that for $x^{k}$ divides it by $k+1$, and for $(1+x)^{\alpha}$ divides it by $\alpha+1$. At the end, the combinatorial play lies on the formula

$$
\int_{0}^{x} t^{\alpha} \mathrm{d} t=\frac{x^{\alpha+1}}{\alpha+1}
$$

the nature of which is more hidden if one uses $\alpha=\frac{m}{n}$, and separates integers $m$ and $n$ in the form:

$$
\frac{n}{m+n} x^{\frac{m+n}{n}}
$$

which was the one used in Newton's time.

Let me here add an excursus for how we may then determine functions $f_{k}$. If as Newton we leave undecided the values of functions $A, B, C, \cdots$, if we consider as proven that the integration in variable $x$ of $(1+x)^{\frac{m}{n}}$ be

$$
\frac{(1+x)^{\frac{m}{n}+1}}{\frac{m}{n}+1}-\frac{1}{\frac{m}{n}+1}
$$

so avoiding case $\frac{m}{n}+1=0$, and if we moreover accept to integrate a series term by term, according to Descartes' undeter- 
mined coefficients method extended to power series in $x$, a cascade of equalities is obtained. The presentation is being facilitated by the numbering Newton had chosen, with the alphabetical order and his iterative writing with products. The identity

$$
\begin{aligned}
f_{1}\left(\frac{m}{n}\right) x+f_{2}\left(\frac{m}{n}\right) f_{1}\left(\frac{m}{n}\right) \frac{x^{2}}{2}+f_{3}\left(\frac{m}{n}\right) f_{2}\left(\frac{m}{n}\right) f_{1}\left(\frac{m}{n}\right) \frac{x^{3}}{3}+\cdots \\
=-\frac{1}{\frac{m}{n}+1}+\frac{1}{\frac{m}{n}+1} f_{1}\left(\frac{m}{n}+1\right)+\frac{1}{\frac{m}{n}+1} f_{2}\left(\frac{m}{n}+1\right) f_{1}\left(\frac{m}{n}+1\right) x \\
\quad+\frac{1}{\frac{m}{n}+1} f_{3}\left(\frac{m}{n}+1\right) f_{2}\left(\frac{m}{n}+1\right) f_{1}\left(\frac{m}{n}+1\right) x^{2}+\cdots
\end{aligned}
$$

yields in fact $f_{1}\left(\frac{m}{n}+1\right)=1$. It is here that the generality of the computation on the variable must imply as well that

$$
f_{1}\left(\frac{m}{n}\right)=1 \text {. }
$$

The second equality yields,

$$
\frac{1}{\frac{m}{n}+1} f_{2}\left(\frac{m}{n}+1\right) f_{1}\left(\frac{m}{n}+1\right)=f_{1}\left(\frac{m}{n}\right),
$$

and by using what has been previously proved, we get

$$
f_{2}\left(\frac{m}{n}+1\right)=\frac{m}{n}+1 \text {. }
$$

With the same procedure on the variable $\frac{m}{n}$, we deduce

$$
f_{2}\left(\frac{m}{n}\right)=\frac{m}{n} .
$$

The third equality is reduced to

$$
\frac{1}{\frac{m}{n}+1} f_{2}\left(\frac{m}{n}+1\right)\left(\frac{m}{n}+1\right)=\frac{1}{2} \frac{m}{n},
$$

that is:

$$
f_{2}\left(\frac{m}{n}+1\right)=\frac{1}{2} \frac{m}{n} .
$$

So we see precisely a unit less and division by an integer having a unit more. So that

$$
f_{2}\left(\frac{m}{n}\right)=\frac{1}{2}\left(\frac{m}{n}-1\right)
$$

The possibility of a solution leads in effect, and for

$$
k \geq 2, f_{k}\left(\frac{m}{n}\right)=\frac{\frac{m}{n}-(k-1)+1}{k-1} .
$$

I have doubts this last proof (that I named an excursus) could have been thought by Newton. Not because there are technicalities unproved with the handling of series, but because the core of the proof is the form of a function. As I went from $x$ to $x$ +1 , or perhaps more properly said, from $m / n$ to $(m+n) / n$. I think the idea of a function came only once integral calculus was understood. I so have not used such changes on functions for the proofs I gave concerning Newton's writing of the binomial formula and what one may deduce for integration theory ${ }^{16}$. However, to the list I gave of presuppositions for the validity of Newton's show to Leibniz, I have to add that integration was indeed supposed to be an additive process. Was it not what Newton intended to explain by exhibiting precisely series, on which he wrote in his memorandum? That the integration process was additive could have been confirmed for Newton by the very result Mercator had obtained with (2)'. Mercator was not using a priori considerations on integration, playing precisely with Riemann sums as we will see, from which the additive property of integration on functions is obvious. We may also think that Newton used what Cavalieri had shown earlier with his very specific figures adding surfaces from addition of lengths in his Geometria indivisibilibus, and other works on indivisibles. We also know that, at least for some integers, the result

$$
\int_{0}^{x} t^{n} \mathrm{~d} t=\frac{x^{n+1}}{n+1}
$$

was important to Cavalieri.

\section{Mercator's Results as Presented to the Royal Society and an Addition by Huygens}

My second step is to check an earlier use of the binomial formula and of power series ${ }^{17}$. As announced, I take the presentation by Mercator in 1668, published in the issue of the Philosophical Transactions dated Monday, $17^{\text {th }}$ August 1668 . The brochure (Figure 3) gave two analysis of books done by John Wallis, the latest being that of a Logarithmotechnia.

Wallis presented it in the form of a letter to Lord Viscount Brouncker ${ }^{18}$, dated July 8 in Oxford. Brouncker had previously worked on similar techniques on the hyperbola. So that this is a good example on how the Royal Society worked, outside official meetings using an active correspondence. There too is a proof of a few pages in a second letter of Wallis dated August 8; it had been specifically requested by Brouncker on August $3^{\text {rd }}$. In this issue, there is an extract provided by Mercator himself of his Logarithmotechnia. This book was appearing the same year in London. All these texts are accompanied by two figures only, by which Wallis attracted even more attention they resemble figures found in his Arithmetica infinitorum, already twelve years old (Figures 4 and 5).

If Wallis reported on the book, it is in part because there was "an accurate and subtle construction of logarithms". It is a numerical display, and explains the reason why Mercator's name is famous. But it was also clear Mercator had a way of "squaring of the hyperbole" ${ }^{\prime 19}$, as Wallis named it.

\footnotetext{
${ }^{16}$ However I considered it was then easy to deduce the integration between 0 and of $\mathrm{x}$ to power $\mathrm{n}$ from the primitive of a binomial with any power.

${ }^{17} \mathrm{I}$ am not considering here the way James Gregory, in a letter dated 1670 , proved the binomial formula by using an interpolation. Recall that I am not here in the quest for an archeology of the binomial formula, but looking at the meaning Newton intended to give by presenting this formula to Leibniz, where the encrypted messages are given.

${ }^{18}$ Quoting Lord Viscount Brouncker was relevant, as this member of the Royal Society had published in the same third volume of the Philosophical Transactions some results on The Squaring of the Hyperbola by an infinite Series of rational Numbers (p. 645-649).

${ }^{19}$ The quotation in Latin is page 753 in the third volume of Philosophical Transactions, and the reference made to Figure 1 is to the figure provided with the figure here numbered as Figure 4.
} 


\section{Quxe huic fubjungitnr. Oradratura Hyperbcle, elegans admodum elt at- que ingeniofs. Nempe ad hunc fenfun. v.lig.r.}

Figure (a).

The word "quadrature" (see Figures (a) and (b)) lost a large part of its meaning, in the sense that no square with an equal area as the area of a hyperbolic segment is seen. Finding a series seems to be the new name for quadrature, but for sure Leibniz and the Bernoulli brothers will give a different meaning to quadrature, the one almost the same we use today when speaking of different quadratures one has to achieve for differ- ential equations. In fact, any mathematician of the time knew that this was related to quadratures due to Gregory of SaintVincent. This author was later quoted in the presentation by Wallis. But few readers could find a link between this statement on Gregory of Saint-Vincent and the paraphernalia of algebraic formulas Mercator presented ${ }^{20}$.

\section{Sunt autem ea piura (ut ex Grigerii de San\{to Virichtis, áliorunque poit ilium, decteina conltat) tanqu in logatrithmi arithmérice proportionalium}

Figure (b).

I think the following modern terminology will be enough to understand Mercator's computations (see Figure 2). I directly start with "Riemann sums"21.

\section{(741) Numb.38. PHILOSOP H ICAL TR ANSACTIONS.}

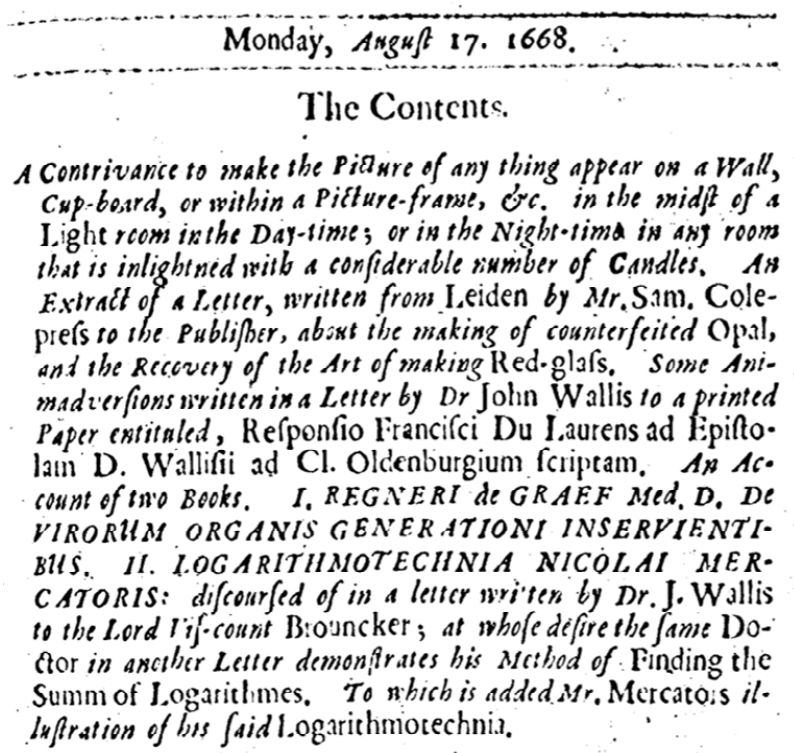

Figure 3.

The presentation page of the issue of the Philosophical Transactions where Mercator's ideas were presented, and at the end of this presentation, the announcement of the two figures about the "sum of Logarithms", which is just series (3)'.

\footnotetext{
${ }^{20}$ The quotation is page 758 in the third volume of Philosophical Transactions.

${ }^{21}$ The anachronistic mention of Riemann sums to define integrals is useful to understand how long it took to get a definition of integration different from the simple inverse of derivation. But we know Riemann sums were used for finding centres of gravity, volumes and for example in gauging methods for ships.
}

$$
S_{n}(f)=\frac{x}{n} \sum_{k=0}^{n-1} f\left(\frac{k}{n} x\right)
$$

for the integral $\int_{0}^{x} \frac{\mathrm{d} t}{1+t}$, where I put $f(x)=\frac{1}{1+x}$. Then

$$
S_{n}(f)=\frac{x}{n} \sum_{k=0}^{n-1} \frac{1}{1+\frac{k}{n} x} .
$$

These Riemann sums have equal steps, and this is precisely such equal steps we see in Mercator's figure with four parallel lines (Figure 4). We also see such equal steps in Figure 5 by Wallis. Binomial formula provides summation of the series

$$
\frac{1}{1+\frac{k}{n} x}=\sum_{m=0}^{\infty}(-1)^{m}\left(\frac{k}{n} x\right)^{m}
$$

and so we may write, using an inversion of the order of summation:

$$
\begin{aligned}
S_{n}(f) & =\frac{x}{n} \sum_{k=0}^{n-1} \sum_{m=0}^{\infty}(-1)^{m}\left(\frac{k}{n} x\right)^{m}=\sum_{m=0}^{\infty} \sum_{k=0}^{n-1}(-1)^{m}\left(\frac{k}{n} x\right)^{m} \frac{x}{n} \\
& =\sum_{m=0}^{\infty}(-1)^{m}\left(\frac{x}{n}\right)^{m+1} \sum_{k=0}^{n-1} k^{n}=\sum_{m=0}^{\infty}(-1)^{m} x^{m+1}\left(\frac{1}{n^{m+1}} \sum_{k=0}^{n-1} k^{m}\right)
\end{aligned}
$$

The last sum appearing is the Riemann sum, with equal steps, $\frac{1}{n} \sum_{k=0}^{n-1}\left(\frac{k}{n}\right)^{m}$ which is related to the integral of $x^{m}$ between 0 and 1 . So that when one goes to the limit in $n$,

$$
\begin{aligned}
\ln (1+x) & =\int_{0}^{x} \frac{\mathrm{d} t}{1+t}=\lim _{n \rightarrow \infty} S_{n}(f)=\sum_{m=0}^{\infty}(-1)^{m} x^{m+1} \lim _{n \rightarrow \infty} \frac{1}{n} \sum_{k=0}^{n-1}\left(\frac{k}{n}\right)^{m} \\
& =\sum_{m=0}^{\infty} \frac{x^{m+1}}{m+1}
\end{aligned}
$$

Outside convergence problems with inverting orders in summations and taking limits, questions, which shall not be treated seriously before Cauchy and Gauss in the early $19^{\text {th }}$ century, we see that integration theory is taken by Mercator according to two points of view. One is the numerical one, that is obtaining 


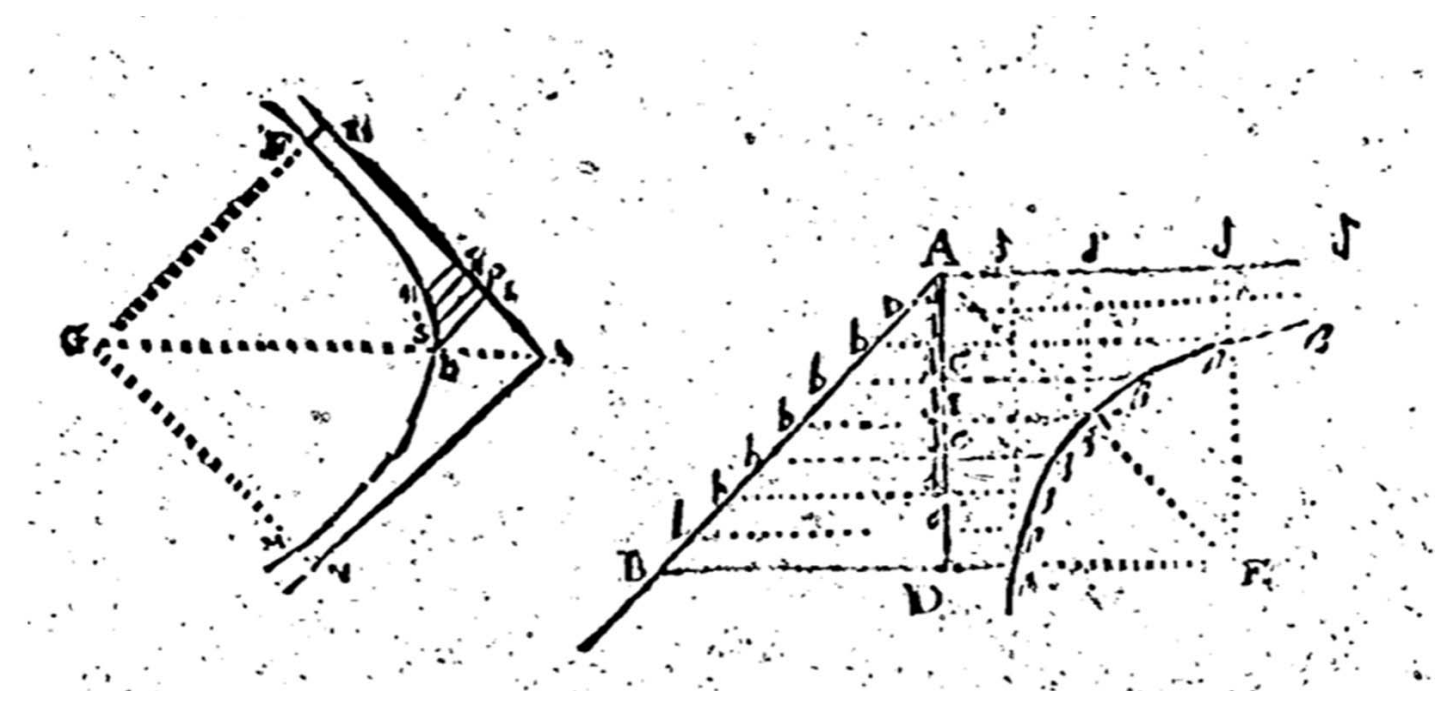

Figures 4, 5 .

The two figures published under $\mathrm{n} 38$ in Philosophical Transactions for August $17^{\text {th }} 1668$ (this appears on page 756), the second one being close to a figure in Arithmetica infinitorum (proposition XCV): one clearly sees parallel lines at equal intervals like in many drawings on indivisibles, four parallel lines only in the first figure.

an integral by Riemann sums of constants steps, so that

$$
\int_{0}^{1} x^{m} \mathrm{~d} x=\lim _{n \rightarrow \infty}\left(\frac{1}{n} \sum_{k=0}^{n-1}\left(\frac{k}{n}\right)^{m}\right)=\frac{1}{m+1} .
$$

The last equality uses a result known for a long time in Arithmetic (at least for small integers $m$ ), which precisely was the main object in Wallis' Arithmetica infinitorum, published in 1656. In place of an explicit limit, Wallis used a fraction with an infinite number of terms, both for the numerator and the denominator: he thus used an indeterminate integer $n$, having first made a change of scale in the variable as well as on the function. But this is not relevant for the present study.

The other integration theory used by Mercator is the logarithmic result:

$$
\int_{0}^{x} \frac{\mathrm{d} t}{1+t}=\ln (1+x) .
$$

This had been found by Gregory of Saint-Vincent. More precisely the Flemish scientist had found that the variable area under a hyperbola using an abscissa $x$, something we write now as $\int_{1}^{x} \frac{\mathrm{d} t}{t}=F(x)$, satisfies the relation:

$$
F(\sqrt{a b})=\frac{F(a)+F(b)}{2} .
$$

In fact, Gregory expressed it geometrically by proving what amounts to the following equality for areas:

$$
F(\sqrt{a b})-F(a)=F(b)-F(\sqrt{a b}) \text {. }
$$

This relation is not what Wallis and Mercator explicitly used from Gregory of Saint-Vincent: as they considered there was the expression of a logarithm (precisely because of (4)). These conclusions had been expressed in 1649 by Antonio Alfonso de Sarasa (see Figure 6 for a translation of this polemical title in his book). He wrote under the guidance of Gregory of SaintVincent, as may be checked form the manuscripts kept in the

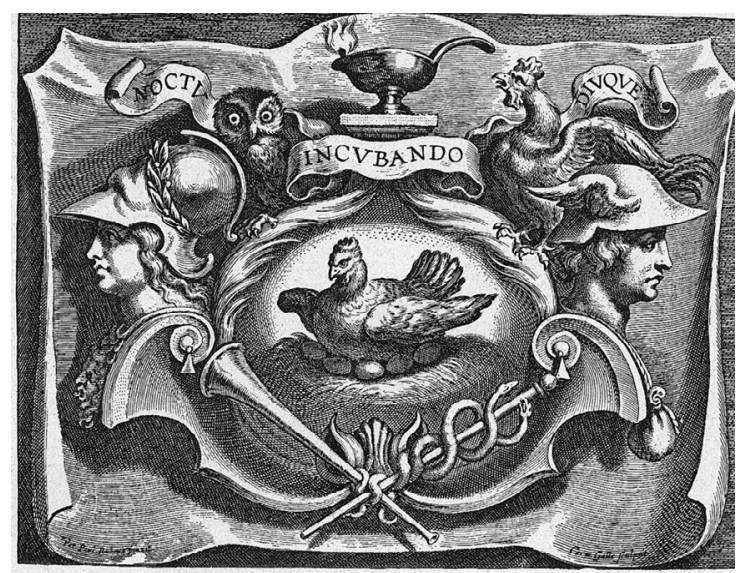

In this proposition, two things are predicted by the person who claims it:

1. the proposition probably requires something far more difficult than the quadrature itself

2. squaring the circle by the Reverend Father Gregory of SaintVincent loses itself in this still unsolved problem. By this, this person suggests that the solution to the problem of squaring the circle will be released, if one overcomes the defect that was indicated in the solution of the problem this person gave.

Author P. Alphonse Antoine de Sarasa from the Society of Jesus Antwerp.

\section{Figure 6.}

Translation of the title of the booklet by de Sarasa in 1649, where logarithms are identified with "hyperbolic spaces" and associated vignette of the Plantin's press, with an allegory on meditation, as well as on financial difficulties to publish books.

Royal Library in Brussels (Mss. 5770-57793).

On the $17^{\text {th }}$ of October 1668 , only two months after the presentation in London by Wallis and Mercator in the issue of the Philosophical Transactions, Christiaan Huygens insisted in a regular meeting of the Paris Academy of sciences on the true origin of the computation involving logarithms. He even drew a 
figure (Figure 7) that is very similar to that of Mercator, and provided a very short explanation (Figure 4).

Or cette dimension de l'hyperbole sert aussy a trouver les logarithmes avec facilité parce que ces espaces hyperboliques comme VRHF, BIHF sont tousiours entre eulx comme la raison de $V R$ à $F H$ est à la raison de $B I$ a $F H$ ce que Gregorius de Sancto Vincentio a monstré le premier $^{22}$.

Such a simple expression of the logarithmic property may astonish the historian, but not the one who knows that Huygens had truly discovered logarithms only some years before, and had too corresponded with the then aged Gregory of SaintVincent who explained to him his intellectual trajectory. In fact Huygens was oversimplifying the expression of this mathematician that we will have to study in our next step. This is also frequent in history of mathematics: something that took years to be understood, once published is viewed as obvious by a new generation, or better said as new bases to build new things. For the moment, it is enough to interpret this Huygens' sentence in our modern terminology, using the exponential notation but keeping letters as organized in Figure 7, and adding $p l$ in front of VRHF just to mean the area of the "hyperbolic space" as was named by Huygens, and to compare with Mercator's writing.

$$
\left(\frac{B I}{F H}\right)^{\frac{p l V R H F}{p l B I H F}}=\frac{V R}{F H}
$$

This amounts to what Gregory of Saint-Vincent had also proved, as will be seen in my next step. Huygens immediately transferred this result in "numerical" terms, and so forgot every precaution about proportion theory. He made it clear that the use of logarithms justified this direct way.

C'est a dire si l'on pose des nombres pour BI, VR, FH alors comme l'espace VRHF est a BIHF ainsy sera la difference des logarithmes des nombres $V R, F H$ a la differ-

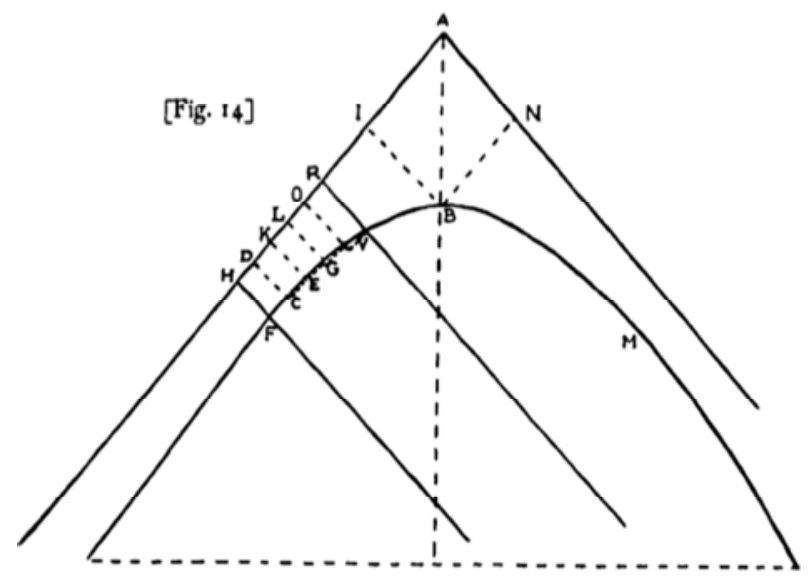

Figure 7

A figure used by Huygens at the Académie des sciences in Paris to explain Mercator's contribution presented in London two months earlier.

\footnotetext{
${ }^{22}$ This dimension of the hyperbola is also used to easily find logarithms as hyperbolic spaces like VRHF and BIHF are always one to another as the ratio of $B I$ is to $F H$. This is what Gregory of Saint-Vincent was the first to show. Huygens, 1668, p. 264.
}

ence des logarithms de $B I, F H^{23}$.

Due to this maintenance of ratios for quantities as well as for logarithms (therefore considered as numerical quantities), there is no need here to specify the kind of logarithms being used. That is any form like $\operatorname{aln} x+b$ will prove convenient. It is enough in fact to have the functional property (4), a property that was up to Mercator at the basis for the construction of logarithmic tables.

\section{Gregory of Saint-Vincent Methods for the Logarithm and for the Exponential}

My third step is to show how Gregory of Saint-Vincent proved equality (4). He used Riemann sums, but with non equal steps. In Figure 8, taken from Opus geometricum published in 1647, Gregory drew parallel lines forming rectangles (called parallelograms in the written text) like FCX, MXG, etc. They cannot be taken for "thick" indivisibles, in the sense that the sizes measured by the abscissas are not uniform ${ }^{24}$. So that rectangles with the same basis $A H$ which are summed up in the right part of the figure (Figure 8), would have to be put in decreasing values according to $C X, X G, G I, I H$, and so give more than the error made by replacing the hyperbola FMELD by rectangles named by three letters only, like FCX, MKG, etc. In a similar but not exactly same way, rectangles appear in a figure (Figure 9) for a general curve in Newton's Principia. One may then pile up such rectangles $a K b I, b L c m$, etc., with the same basis $A B$. The idea is to show how to pile up "small" quantities, while keeping a "small" quantity. Smallness in this figure is provided by length (Figure 9), as it is provided by length $C X$ (larger that $X G, G I$ and $I H$ in Figure 8). What is surprising is that Newton kept unexplained a small rectangle IfFB, drawn in part with dotted lines, which may precisely show the fluxion of the area is the ordinate of the curve, a result not at all mentioned in Gregory's Opus geometricum.

Now I am ready for the fourth step, which is to read proposition 108 in Gregory of Saint-Vincent's Opus geometricum. This result is known as a quadrature of the hyperbola, but there is no quadrature in the old sense, nor in the sense with series that Mercator had used: an equality is obtained between a priori numerically unknown areas.

Proposition 108: Let $A B$ and $A C$ be asymptotes to hyperbola $D E F$, and $D H, E G$ and $C F^{25}$ parallel $^{26}$ to the asymp-

${ }^{23}$ That is if one uses numbers for $B I, V R, F H$, then as space VRHF is to $B I H F$, so is the difference of logarithms of numbers $V R$ and $F H$ to the difference of logarithms of BI and FH. Huygens, 1668, p. 264. I have not checked the original manuscript (Registres de l'académie des sciences, tome III, pp. 138-143), but I am using the very precise edition of the complete works of Huygens (vol. 20, p. 261). Huygens' sentence can be rendered in the following terminology: $\frac{p l V R H F}{p l B I H F}(\ln B I-\ln F H)=\ln V R-\ln F H$.

${ }^{24}$ Cavalieri in 1635 drew parallel straight lines moving in such a way as to cover entirely a figure, and so to generate an area. Such lines were called indivisibles, and so they were supposed without any thickness. Thick indivisibles were later invented in order to link what Cavalieri did to what was done on figures with Riemann sums, seen as geometric approximations to an area.

${ }^{25}$ For analogy reasons, one should prefer the writing FC in this order. But Gregory of Saint-Vincent chose quite often, in a sort of baroque mood, to end a series of letters by inverting the order. As if to close something in the appearance of a figure.

${ }^{26}$ The original text reads as "equidistant". 

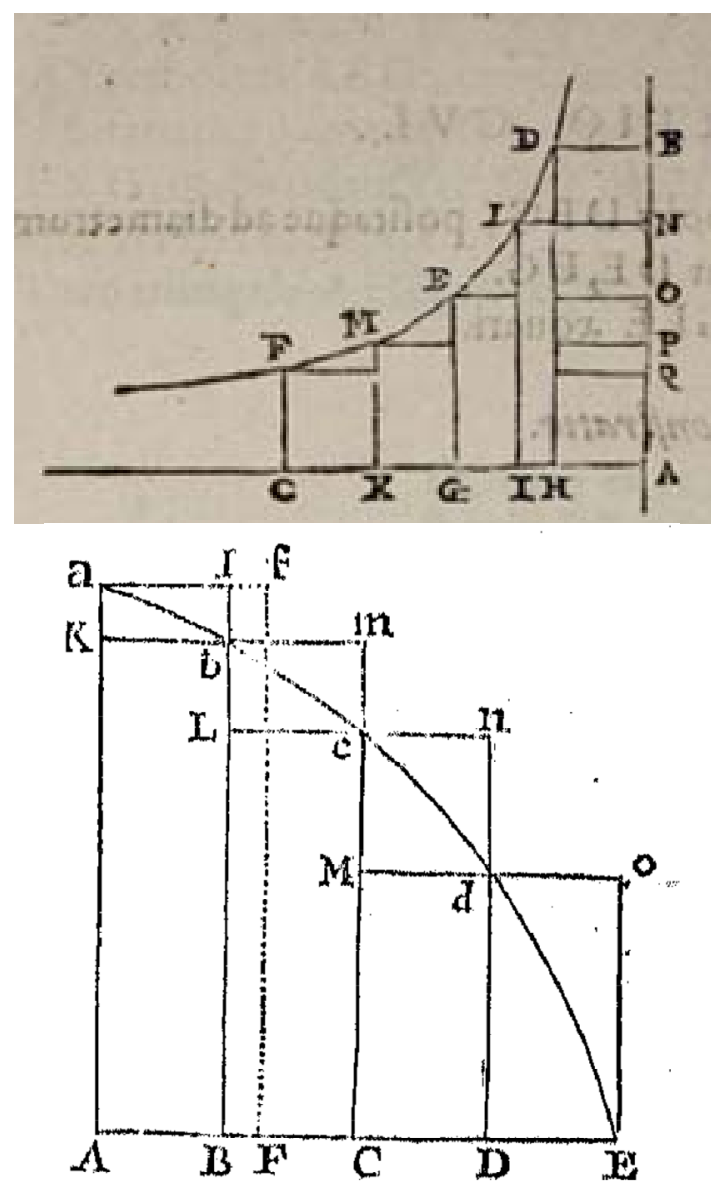

Figures 8, 9 .

Figure of a hyperbola accompanying proposition 108 in Book VI of the Opus geometricum, published in Antwerpen in 1647. The second figure is from Newton's Principia. I chose the last edition (1726, p. 28), which is here the same as in the original 1687 edition, to prove that Newton had not tried to modify the way summation of infinitely small sums worked.

tote $A B$, be in continued proportion ${ }^{27}$. I say that segment $D H G E$ is equal to segment EGCF.

Its proof goes in the following way.

Proof: Let $L I$ be given and put proportional means between $H D M K, E G, C F$, and draw $B D, L N, E W, M P, F Q$ parallel to the asymptote $A C$. Since $D H, L I, E G, M K, F C$, continue the same ratio, $A H, A I, A G, A K, C A$, are proportional $^{28}$ (according to proposition 78 in this book). But since the differences ${ }^{29} \mathrm{HI}, \mathrm{GI}, \mathrm{GK}$, etc., are proportional (Proposition 1 of De progressionibus ${ }^{30}$ ) that $H I$ is to $I G$, $A I$ is to $A G$, that is to say, as $E G$ is to $L I$. This is why parallelograms $L H$ and $E I$ are equal. (by Proposition 14 of this book). Also because $G I$ is to $G K$ as $M K$ to $E G$, paral-

\footnotetext{
${ }^{27}$ Continuous proportion just means: $\frac{D H}{E G}=\frac{E G}{C F}$.

${ }^{28}$ The hyperbola transforms a proportion on the abscissa-axis into one in the ordinate-axis. The ratio of the proportion is reversed in the passage through the hyperbola.

${ }^{29}$ The word difference is here to indicate a term like $\mathrm{HI}=\mathrm{AH}-\mathrm{AI}$, to get a continuous proportion as well.

${ }^{30}$ This is a reference to the second book in Opus geometricum.
}

lelograms EI and MG are also equal. Similarly, parallelogram $F K$ is equal to parallelogram $M G$. So the four parallelograms $L H, E I, M G, F K$ are equal. So the two parallelograms $L H$ and $E I$ cut off from segment $E G H D$ are equal to two parallelograms $M G$ and $F K$ cut off from segment FCEG. Once again, if we set the mean proportional between $D H, L I^{31}, E G$, and between $E G, M K, F C$, is shown in the same way as above, that the parallelograms in segment EGHD are equal to the parallelograms in segment FCEG. And since it can always be done in such a way that the parallelograms cut off from segment $D H E G$ are greater than half segment DHEG and equal to those who are cut off from segment EGFC are also larger than the half of the same segment, it is clear that segment FCEG is equal to segment EGDH (Proposition 116 of De progressionibus). This was to be proved.

We notice that this is a direct procedure in this proof of an equality. It is based on earlier and general proofs in the Opus geometricum, put in book 2. It is related to what Newton will do in 1687 under the name of ultimate ratios.

I am adding Figures 10 to 12 to show that Gregory of Saint-Vincent's procedure, but this time with parallel lines at equal intervals, is used a second time in his book, at book 7, for the ductus planum in plani. Such parallel lines appear as well in Luca Valerio's book on centers of gravity, in the early seventeenth century (Figure 13).

In book 6, to which we return, Gregory of Saint-Vincent went further, and provided a figure (see Figure 14).

Proposition 129. Let $A B^{32}$ and $B C$ be asymptotes of the hyperbola $D F H$, and let $D E, F G$, and $H C^{33}$ be parallel to the asymptote $A B$. Let plane surface $F G C H$ be incommensurable to plane surface $D E G F$. I say the ratio of $D E$ to $F G$ multiplies the ratio of $F G$ to $H C$ as many times quantity $D E G F^{34}$ contains quantity FGCH (Dico rationem $D E$ ad $F G$, toties multiplicare rationem $F G$, ad $H C$, quoties quantitas DECF, continet quantitatem $\mathrm{FGCH})^{35}$.

Proposition 129 in the same book 6 on the hyperbola by Gregory of Saint-Vincent gave the exponential property of transforming a sum into a product. Gregory distinguished a commensurable case (for which the reasoning by computation is direct) and a non-commensurable case, easily proved by a result of equality from Proposition 108. Gregory thus followed the path chosen by Archimedes for his famous theory of the lever in On planes equilibrium. His goal here was to define a real number as an exponent, and as he has no name for it, he called it a procedure of "many times". It refers to what was written earlier as a quotient of areas introduced by $p l$. This explains exponentiation, and is not restricted to rational exponents. Gregory of Saint-Vincent thought in terms of numerical ratios. It can be translated without betraying him by setting

$$
\frac{\operatorname{areaDEGE}}{\operatorname{areaFGCH}}=\alpha,
$$

and in a similar way,

\footnotetext{
${ }^{31} \mathrm{By}$ mistake in the original text $L E$ is written.

${ }^{32} \mathrm{~A}$ is missing in the figure, and should be read at the top left.

${ }^{33}$ This time, the last term $H C$ is written by analogy with the three others.

${ }^{34} \mathrm{By}$ mistake there is a $C$ in place of a $G$.

${ }^{35}$ Gregory of Saint-Vincent used the same expression as in proposition 125 , but the "number of times" involved in the present proposition 129 is an irrational number.
} 


\section{J. G. DHOMBRES} $D_{\text {ex duabus fupet ficiebus vandé habentibus aut } x \text { qualë bafim ortam }}^{\text {vetum }}$ E X P L I C A T IO.
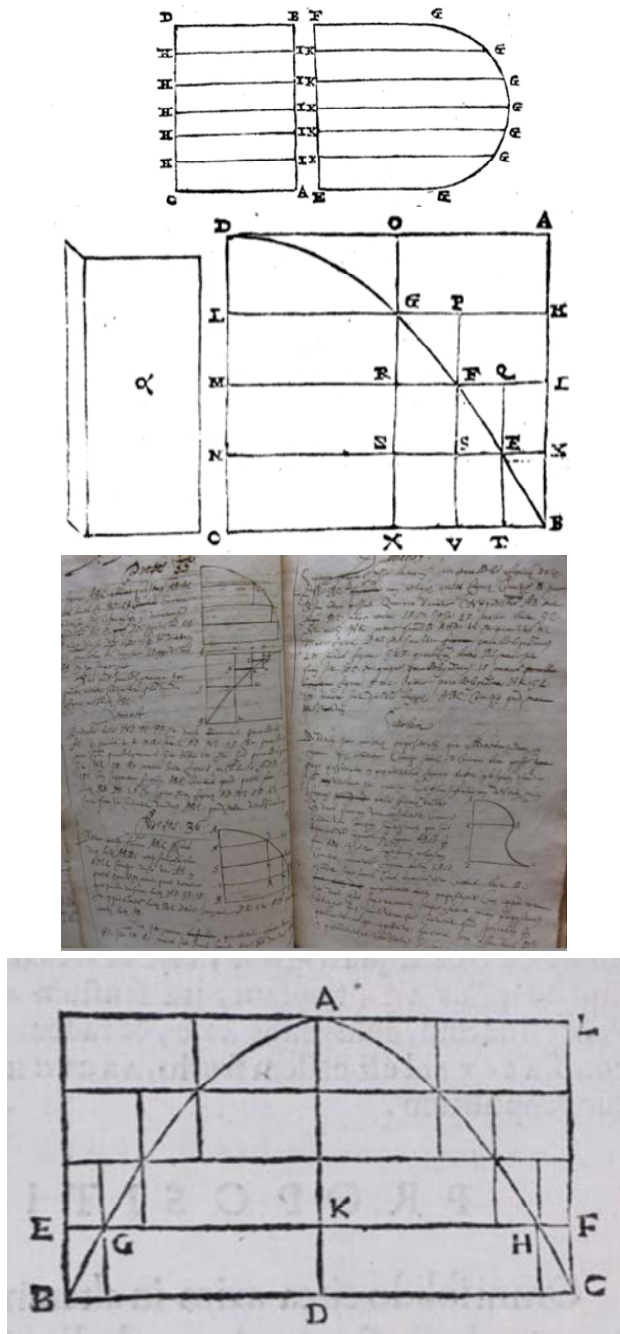

Figures 10 to 13.

One of the first figure to the left in the book on ductus by Gregory of Saint-Vincent, showing parallel lines at equal intervals. It prepares an interpretation for solid geometry. Therefore here there is no approximation procedure. The next figure to the right appears in the third chapter on the ductus, with a general "concave" curve. It exhibits a way to prove that the sum of small rectangles like $G P F R, R F S N$, etc., remains small as being included in $0 A E G$, where $E G$ gives a step for the approximation. All letters are not clearly legible, and $N$, for example, has been inverted by the printer. Next figure is from a manuscript page with drawings from what will become the seventh book on the ductus by Gregory of Saint-Vincent, showing inscribed rectangles for a general curve. One also sees a non concave curve, and this generality is typical of this seventh book of Opus geometricum. Last illustration is a figure from De Centro gravitatis due to Luca Valerio in 1606, which certainly played a role in the scientific education of Gregory of Saint-Vincent. One sees the approximation of the area of a parabola with circumscribed and inscribed rectangles. The difference between these two approximations is shown as an addition of small rectangles, but they are not entirely piled up.

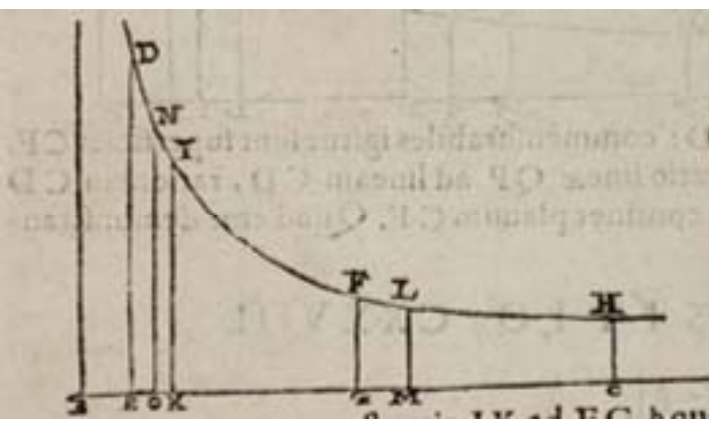

Figure 14.

Figure accompanying proposition 129 in the same book, with parallel lines and no rectangles.

$$
\frac{D E}{F G}=\left(\frac{F G}{H C}\right)^{\beta}
$$

Therefore we have three possibilities only:

$\alpha>\beta, \alpha<\beta, \alpha=\beta$. What is to be proved is that only the last equality is true. It is enough to establish that the previous two inequalities are false. Note that the functional property, which is true for any exponential, is derived here from the geometric evidence of addition of areas (one "sees": $a^{x+y}=a^{x} a^{y}$ ). This property of the exponentiation was not recognized at the time, and almost never quoted by historians ${ }^{36}$. Thus it plays no role in my present story. Except I wanted to show that a mathematician, like Newton in this case, was not always able to see what was important in another one, here Gregory of Saint-Vincent. So that the hope that Leibniz could understand immediately his mention of the binomial formula was certainly fallacious.

\section{More than a Conclusion, and to Go Further}

My conclusion indeed is that by the formulation Newton

${ }^{36}$ If exponentiation was really discovered and correctly defined by Gregory of Saint-Vincent, it does not mean that he explained exponential of base $e$. And so we may understand why Huygens chose to prefer using the already constructed Neperian logarithm (without explicitly thinking it was the inverse of the exponential of base e). What is surprising is that Gregory had everything to have the exponential of base e. A modern notation will make it clear. Suppose that we take three points, named $x_{1}, x_{2}$ and $x_{3}$, as abscissas and corresponding $y$ 's on the hyperbola (the Cartesian equation of which can be written as $x y=k$ ). And denote by area 1 , area 2, area 3 , the successive areas of the hyperbolic segments. What Gregory of Saint-Vincent proved in proposition 129 is that: $\left(\frac{y_{2}}{y_{1}}\right)^{\frac{\text { area } 2}{\operatorname{arcal}}}=\frac{y_{3}}{y_{2}}$. If we define $A=\left(\frac{y_{2}}{y_{1}}\right)^{\frac{1}{\text { areal }}}$, then we have the expression of a ratio in terms of an exponential. That is $A^{\text {area2 }}=\frac{y_{3}}{y_{2}}$ In our modern way of writing, this just means that $e=A^{-\frac{1}{k}}$. Gregory of Saint-Vincent could have proved that his number $e=A^{-\frac{1}{k}}$ was not dependent of the specific hyperbola used, or even have taken $k=1$. He certainly could have proved, just form his result in Proposition 129 that what he did with 1 and 2 to define $A$ would give the same number with 2 and 3 , etc. But he was not thinking in terms of a general representation of positive real numbers (his general ratios) in terms of an exponential. Due to addition of areas, he may see as well that $A^{\text {area2ararea } 3}=\frac{y_{4}}{y_{2}}$. And he may have, $A^{\text {area3 }}=\frac{y_{4}}{y_{3}}$ So that from the well known composition of ratios, $\frac{y_{4}}{y_{2}}=\frac{y_{4}}{y_{3}} \frac{y_{3}}{y_{2}}$, Gregory of Saint-Vincent could have deduced the characteristic exponential property: $A^{\text {areal+area2 }}=A^{\text {areal }} A^{\text {area2 }}$. 
chose for the binomial he could think this was a good way to exhibit to Leibniz the "vice versa", that is the reciprocal link between fluxional operation and integration operation, the two being defined as independent operations. This was at least clear in 1676, when Newton specifically insisted in writing this formula by using a recurrence on coefficients and not an explicit formula for such coefficients, later known as binomial coefficients. At this time, and after a long process, Newton had already obtained fluxions and integration, with separate definitions. So that he then could be impressed by what he saw in the binomial formula, quite independently of the fact that this formula might have been as well at the beginning of his thoughts on the Calculus. Another strong impression could be the fact that what had been done with integration to understand the recurrence for coefficients in the binomial formula, could be done as well with derivation, this time using

$$
\mathrm{d}\left(x^{n}\right)=n x^{n-1} \mathrm{~d} x \text { or } \mathrm{d}(x+1)^{\alpha}=\alpha(1+x)^{\alpha-1}
$$

or more properly said with the equivalence with dots in writing fluxions $^{37}$. This is important if we consider that for Newton, following Leibniz, integration came first, and derivation afterwards. At this time, year 1676, Newton might suppose that Leibniz had obtained the same.

Later, textbooks on the Calculus began by explaining how derivation or integration worked on powers of $x$, rational or irrational, and so insisted far less on the binomial formula, which appeared to be a formula of secondary importance. Such textbooks, following Jean Bernoulli, were based on integration as being defined as the inverse to derivation (so that the appearance of $1 / n+1$ in the integration of $x^{n}$ was not a proof, but the consequence of a definition and of derivation law). In this way, textbooks forgot for a while Riemann sums and numerical methods for approximation of areas or volumes. They however were still used in practice. I warned at the outset that I certainly was not trying here to decide between Leibniz and Newton on the advantages and presentations of Calculus from derivation or from integration: we all know that the differential notation is better than the dots in the sense that a differential can be seen in the writing of an integral, so clearly linking the two operations to have one Calculus only. I so gave my basic assumptions from the Newton memorandum. But I did not need to base my account on an "innocence" of Newton, as I merely "see" what one could get for the discovery of Calculus if Newton's encrypted message was literally read. The advantage of my very restrictive procedure is to avoid complicating the story with the introduction of "indivisibles", which Newton did not mention in the text I chose. In May 1686, Leibniz felt the need to present Cavalieri's work as a start, or on his own terms, the "childhood of a resurgent science" 38 . This seems to contradict his later presentation of integration as a mere inverse of derivation. It was then a pleasure to give some place here to Gregory of Saint-Vincent, as his importance lies in the fact that he specified integration as a process, inventing the notion of a primitive, or indefinite integral. But, under the guidance of Huygens, I associated the Flemish mathematician to Mercator, who preferred to mention Mersenne. This mathematician handled series and algebraic notations, which Gregory of Saint-Vincent scorned or ignored and so could not go much further. Contrary to

\footnotetext{
${ }^{37}$ This idea using derivation or fluxions is what seems to be claimed by Newton in the exchanges in the priority quarrel. See Turnbull, 1960.

${ }^{38}$ Leibniz, 1686, p. 228.
}

Newton, as we have seen in his epistola posterior to Leibniz.

For my specific point of view here, it is the confluence of two specific types of integration with different Riemann sums, as we say today, which gave its numerical strength to Mercator's discovery. We must not forget that it caused a revolution in the establishment of tables of logarithms. John Wallis had only one type of integration due to his very specific notations for Riemann sums with constant steps. It could have led to another revolution in Newton's mind, once he saw that the fluxion of an area was precisely the function to be integrated. I have not tried here to check what the information from Gregory of SaintVincent and from Mercator could have brought to Leibniz, but in the mind of the German mathematician, infinitesimals in general played a major role, while we have seen Newton trying to restrict to the integration process, then deducing the derivation process. There was a different way for Calculus, and the Leibniz way was apparently the one privileged, outside applications of Calculus to various practical domains such that ships stability, till Cauchy proved in 1821 the fundamental theorem of Calculus showing that integration via Riemann sums indeed corresponded to integration as inverse to derivation.

\section{REFERENCES}

Dhombres, J. (2014). Could or should Gregory of Saint-Vincent have had to use indivisibles to present his own quadrature of the hyperbola that led to the logarithm and to the exponential? To appear in a book by Birkhaüser Verlag, directed by Vincent Jullien, and entitled: Indivisibles.

Dhombres, J. (2014). Les savoirs mathématiques et leurs pratiques culturelles. Paris: Hermann.

Guicciardini, N. (1998). Did Newton use his calculus in the principia? Centaurus, 40, 303-344.

http://dx.doi.org/10.1111/j.1600-0498.1998.tb00536.x

Harper, W. L. (2011). Isaac Newton's scientific method. Oxford: Oxford University Press.

Huygens, C. (1668). Sur la quadrature arithmétique de l'hyperbole par Mercator et sur la méthode qui en résulte pour calculer les logarithms, d'après les registres de l'académie pour le 17 octobre 1668. Oeuvres de Huygens, 20, 261.

Koyré, A. (1968). Etudes newtoniennes. Paris: Gallimard.

Leibniz, G. W. (1686). De geometria recondita et analysi indivisibilium atque infinitorum. Acta Eruditorum. In Math. Schriften, V, 228.

Mercator, N. (1668). Logarithmotechnia: Sive methodus construendi Logarithmos, nova, accurate, \& facilis, scripto antehàc communicata, Anno Sc. 1667. Londres: Wilhelm Godbid.

Newton, I. (1999). The principia: Mathematical principles of natural philosophy by Isaac Newton (translated by I. Bernard Cohen, Anne Whitman). Berkeley: University of California Press.

Panza, M. (2005). Newton et l'origine de l'Analyse, 1664-1666. Paris: Blanchard.

Pensivy, M. (1987). Jalons historiques pour une épistémologie de la série infinie du binôme. Cahiers d'Histoire et de Philosophie des sciences.

Rupert Hall, A. (1980). Philosophers at war. The quarrel between Newton and Leibniz. Cambridge: Cambridge University Press. http://dx.doi.org/10.1017/CBO9780511524066

Turnbull, H. W. (1960). The correspondance of Isaac Newton, Vol. II, 1676-1687. Cambridge: At the University Press.

Whiteside, D. T. (1960). Patterns of mathematical thought in the later sevententh century. Archive for History of Exact Sciences, 1, 179388. http://dx.doi.org/10.1007/BF00327940

Whiteside, D. T. (1961). Newton's discovery of the general binomial theorem. Mathematical Gazette, 45, 175-180. http://dx.doi.org/10.2307/3612767

Whiteside, D. T. (1967-1974). The mathematical papers of Isaac Newton. Cambridge: Cambridge University Press. 